\title{
Flora das cangas da Serra dos Carajás, Pará, Brasil: Dryopteridaceae
} Flora of the cangas of the Serra dos Carajás, Pará, Brazil: Dryopteridaceae

\author{
Ingridy Oliveira Moura ${ }^{1} \&$ Alexandre Salino ${ }^{1,2}$
}

\begin{abstract}
Resumo
Este estudo trata dos táxons de Dryopteridaceae encontrados nas formações ferríferas da Serra dos Carajás, estado do Pará, com descrições, ilustrações, distribuição geográfica e comentários. Na área estudada foram registrados quatro gêneros e quatro espécies: Ctenitis nigrovenia, Dryopteris huberi, Elaphoglossum glabellum e Polybotrya sorbifolia.
\end{abstract}

Palavras-chave: Amazônia, Ctenitis, Dryopteris, Elaphoglossum, Polybotrya, samambaias.

\begin{abstract}
This study addressed the Dryopteridaceae taxa recorded in ferruginous formations of Serra dos Carajás, Pará state, bringing descriptions, illustrations, geographical distribution, and comments. In the study area four genera and four species were recorded: Ctenitis nigrovenia, Dryopteris huberi, Elaphoglossum glabellum and Polybotrya sorbifolia.
\end{abstract}

Key words: Amazonia, Ctenitis, Dryopteris, Elaphoglossum, Polybotrya, ferns.

\section{Dryopteridaceae}

Plantas terrestres, rupícolas, hemiepifíticas ou epifíticas. Caule ereto a longo reptante ou escandente, com muitas escamas persistentes. Frondes monomorfas ou dimorfas. Lâmina simples ou 1-5-pinada ou mais dividida. Venação livre ou anastomosada, com ou sem vênulas inclusas livres. Soros arredondados, oblongos, lineares ou acrosticóides. Indúsio presente ou ausente. Esporos monoletes. Família com ampla distribuição mundial com ca. 40-45 gêneros e 1700 espécies (Smith et al. 2006). No Brasil ocorrem 181 espécies, sendo 21 registradas para o estado do Pará (Prado et al. 2015).

\section{Chave de identificação dos gêneros de Dryopteridaceae das cangas da Serra dos Carajás}

1. Lâmina simples; frondes dimorfas

1'. Lâmina 1-pinada, 1-pinado-pinatífida ou 3-pinado-pinatífida; frondes monomorfas ou dimorfas.......2

2. Frondes dimorfas.

4. Polybotrya

2'. Frondes monomorfas

3. Tricomas catenados presentes nos eixos da lâmina . Dryopteris

\section{Ctenitis (C.Chr.) C.Chr.}

Ctenitis é composto por plantas terrícolas ou rupícolas, que se diferencia dos outros gêneros da família por apresentar tricomas catenados principalmente nos eixos das frondes (Viveros 2016). Caule ereto a decumbente, raramente reptante, recoberto por escamas; frondes monomorfas; lâmina 1-pinado-pinatífida à 4-pinada; sulcos adaxiais ausentes ou se presentes não decurrentes entre si; Nervuras livres; soros arredondados; indúsio ausente ou presente, redondo a reniforme; persistente ou decíduo. Gênero de distribuição pantropical, é um dos mais diversos da família Dryopteridaceae (Smith et al. 2006),

\footnotetext{
${ }^{1}$ Universidade Federal de Minas Gerais, Av. Presidente Antônio Carlos 6627, Pampulha, 31270-901, Belo Horizonte, MG, Brasil.

${ }^{2}$ Autor para correspondência: salinobh@gmail.com
} 
com cerca de 70-80 espécies (Viveros \& Salino 2015). No Brasil ocorrem 20 espécies, das quais três no Pará (Viveros 2016) e duas na Serra dos Carajás (Arruda 2014).

1.1. Ctenitis nigrovenia (Christ) Copel., Gen. Fil. (Copeland) 124. 1947.

Nephrodium nigrovenium Christ, Bot. Gaz. 20(12): 545. 1895.

Figs. $1 \mathrm{a} ; 2 \mathrm{a}$

Plantas terrícolas ou rupícolas. Caule decumbente a ereto, com escamas castanhoescuras. Frondes monomorfas, 34-77 cm compr. Pecíolo 11-35 cm × 1,1-3,2 mm, paleáceo, recoberto por escamas semelhantes às do caule, tricomas catenados e glandulares. Lâmina 23-42 cm compr., 1-pinado-pinatífida à 1-pinadopinatisecta. Pinas 8-12 × 2,4-3,4 cm, incisão de $3 / 4$ ou maior do que a distância entre a margem e a costa, tecido laminar e costa com esparsos tricomas baciliformes na face abaxial e tricomas catenados esparsos sobre as nervuras em ambas as faces; raque e costa abaxial com esparsas escamas lanceoladas, subclatradas, castanhas a nigrescentes. Segmentos com margem glabra. Nervuras simples ou 1-furcadas, as basais de segmentos adjacentes unindo-se à margem bem acima do enseio. Soros medianos; indúsio glabro. Material selecionado: Canaã dos Carajás, Serra Sul, corpo A, 6²0'59' S, 50²5'49' W, 688 m, 14.II.2010, T.E. Almeida et al. 2178 (BHCB); Serra Sul, corpo B, 6²0'36'S, 50²4'30'”W, 575 m, 24.V.2012, A. Salino et al. 15291 (BHCB); Serra Sul, corpo C, 6²4'12'"S, $50^{\circ} 23^{\prime} 57^{\prime}$ 'W, 440 m, 28.I.2012, L.V.C. Silva 1164 (BHCB); Serra Sul, 6²4'44'”S, 50¹9'56' W, 750 m, 02.X.2009, P.L. Viana 4336 (BHCB); Serra do Tarzan, 6¹9'34''S, 5007'13'”W, 540 m, 09.II.2010, A. Salino et al. 15145 (BHCB); Parauapebas: Serra da Bocaina, 6¹8'50''S, 4953'35' W, 660 m, 13.II.2012, A. Salino et al. 15178 (BHCB); Serra Norte, corpo N4, 18.V.2012, A. Salino et al. 15212 (BHCB) .

Na Flona de Carajás também ocorre Ctenitis refulgens (Klotzsch ex Mett.) C.Chr. ex Vareschi (Arruda 2014) que se diferencia de C. nigrovenia pelas pinas com incisão de até $2 / 3$ da distância entre a margem e a costa, margens dos segmentos com tricomas catenados, nervuras basais de segmentos adjacentes unindo-se no enseio ou terminando antes do enseio e indúsio ausente.

Neotropical. Brasil: BA, MT, PA (Viveros 2016). Serra dos Carajás: Serra Norte: N4, Serra Sul: S11-A, S11-B, S11-C, Serra do Tarzan e Serra da Bocaina. Em barrancos próximos a igarapés e cursos d'água, entre 440 e $750 \mathrm{~m}$ de altitude.

\section{Dryopteris Adans.}

Dryopteris é composto por plantas terrícolas e rupícolas, ocasionalmente epífitas, com caule ereto a curto-reptante; frondes monomorfas a subdimorfas; lâmina 1-3-pinado-pinatífida, membranácea a coriácea, lanceolada a deltóidelanceolada, com ápice pinatífido; pinas lineares a lanceoladas; pínulas sésseis a curto-pecioluladas, ápice agudo a obtuso; nervuras livres, 1-2-furcadas; soros arredondados; indúsio orbicular-reniforme a reniforme, fixo no enseio ou raramente peltado. Gênero de distribuição cosmopolita com cerca de 225 espécies, das quais 30 no Novo Mundo e a maioria na América do Norte (Fraser-Jenkins 1986; Mickel \& Smith 2004; Zhang et al. 2012). No Brasil ocorrem três espécies, das quais duas no Pará (Prado et al. 2014) e uma na Serra dos Carajás (Arruda 2014).

2.1. Dryopteris huberi (Christ) C.Chr., Index Filic., Suppl. 1: 34. 1913.

Aspidium huberi Christ, Hedwigia 45: 192. 1906.

Figs. $1 b ; 2 b$

Plantas rupícolas. Caule decumbente, com escamas linear-lanceoladas, ápice filiforme e retorcido, concolores, castanhas. Frondes monomorfas, 17-64,5 cm compr. Pecíolo 4,5-21 cm $\times 0,6-2,7 \mathrm{~mm}$, paleáceo, com escamas semelhantes às do caule e tricomas glandulares. Lâmina 12,543,5 cm compr., 2-pinado-pinatífida a 3-pinadopinatífida; raque com tricomas glandulares; pinas alternas, 5-8 × 2,4-4,7 cm, margem glabra, tricomas glandulares conspícuos no tecido laminar, costa e nervuras em ambas as faces, pínulas acroscópicas basais mais desenvolvidas do que as basioscópicas basais. Nervuras 1-2-furcadas. Soros arredondados, medianos a submarginais; indúsio reniforme, decíduo, com tricomas glandulares.

Material selecionado: Canaã dos Carajás, Serra Sul, corpo A, 6 ${ }^{\circ} 19^{\prime} 43^{\prime}$ 'S, 50 $20^{\circ}{ }^{\prime} 18^{\prime \prime} \mathrm{W}, 737 \mathrm{~m}, 5 . \mathrm{III} .2010$, T.E. Almeida et al. 2212 (BHCB); Serra Sul, corpo C, 6023'53'"S, 50²3'32”'W, 790 m, 28.I.2012, L.V.C. Silva et al. 1151 (BHCB); Serra Sul, 6²4'38"S, 50¹9'36”'W, 806 m, 1.VI.2010, D.T. Souza et al. 1123 (BHCB); Serra do Tarzan, $6^{\circ} 19^{\prime} 46^{\prime}$ 'S, $50^{\circ} 07^{\prime} 35^{\prime}$ 'W, 09.II.2012, A.J. Arruda et al. 586 (BHCB); Parauapebas: Serra da Bocaina, 13.II.2012, A.J. Arruda et al. 612 (BHCB).

Dryopteris huberi pode ser facilmente confundido com Dryopteris patula (Sw.) Underw., mas difere desta pelo caule decumbente e por possuir uma ala com coloração verde na face adaxial da costa.

Endêmica do Brasil: GO, MT, PA (Prado et al. 2014). Serra dos Carajás: Serra da Bocaina, Serra 


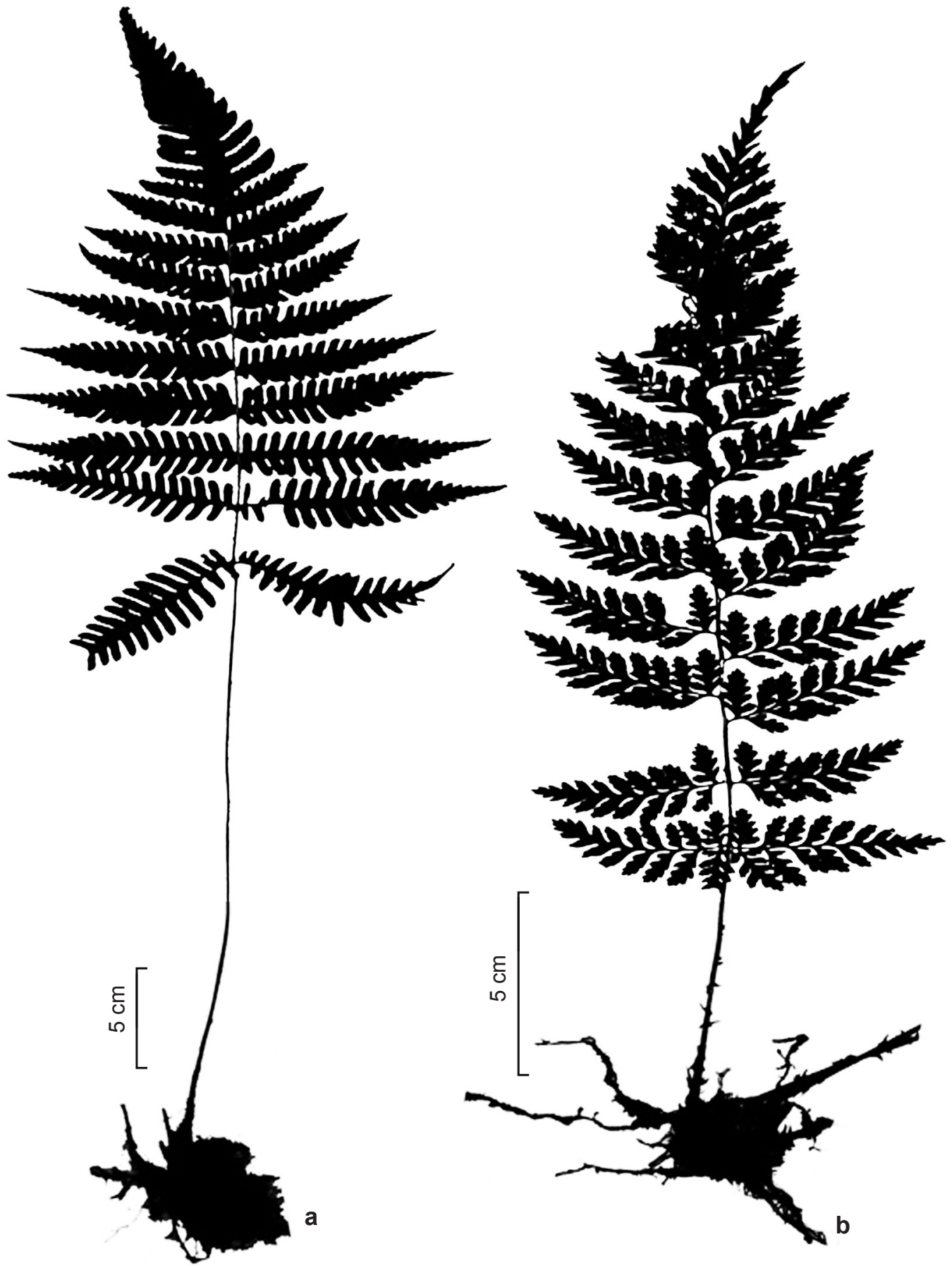

Figura 1 - a. Ctenitis nigrovenia - fronde; b. Dryopteris huberi - fronde (a. A. Salino 15178; b. L.V.C. Silva 1151). Figure 1- a. Ctenitis nigrovenia - frond; b. Dryopteris huberi - frond (a. A. Salino 15178; b. L.V.C. Silva 1151). 
Sul: S11-A, S11-C, e Serra do Tarzan, em floresta decídua sobre canga, em paredões rochosos e sobre rochas em ambientes úmidos geralmente próximos à cursos d'água, entre 700 e $806 \mathrm{~m}$ de altitude.

\section{Elaphoglossum Schott. ex J.Sm.}

Elaphoglossum é composto por plantas epífitas, rupícolas ou terrícolas, que se caracterizam por apresentar frondes dimorfas, lâmina geralmente simples, raramente flabelada ou palmada, nervuras livres ou, raramente, parcialmente anastomosadas e soros acrosticóides. Gênero de distribuição pantropical e sul-temperada (Tryon \& Tryon 1982), com mais de 600 espécies (Mickel \& Smith 2004), das quais aproximadamente 450 habitam a região Neotropical (Skog et al. 2004). No Brasil ocorrem 87 espécies, das quais sete são citadas para o estado do Pará (Prado et al. 2015), quatro na Serra dos Carajás (Arruda 2014) e apenas uma nas cangas.

\subsection{Elaphoglossum glabellum J.Sm., London J.} Bot. 1: 197. 1842.

Fig. 3c

Plantas epífitas. Caule curto-reptante, recoberto por escamas lanceoladas, castanhoescuras, fimbriadas na margem. Frondes 13,5-31,5 $\mathrm{cm}$ compr., coriáceas, eretas, as férteis geralmente menores do que as estéreis. Pecíolos 2,3-9 cm ×1,3 $\mathrm{mm}$, paleáceos, glabros ou com poucas escamas na base e semelhantes às do caule. Lâmina linearelíptica, base longo-decurrente e ápice acuminado, glabra ou com esparsas escamas estreladas na face abaxial, margens leve a fortemente revolutas; lâmina estéril 13,5-22,5 ×0,5-1,3 cm, lâmina fértil $11,2 \times 1,3 \mathrm{~cm}$. Nervuras livres a 1 -furcadas.

Material selecionado: Canaã do Carajás, Serra Sul, Corpo D, 6²3'46"'S, 50¹6’39' W, 700 m, 17.III.2009, P.L. Viana et al. 4115 (BHCB); Serra Sul, 6 ${ }^{\circ} 20^{\prime} 53^{\prime \prime}$, $50^{\circ} 25^{\prime} 46^{\prime \prime} \mathrm{W}, 718 \mathrm{~m}, 14 . \mathrm{II} .2010$, D.T. Souza et al. 1083 (BHCB).

Material adicional examinado: BRASIL. MINAS GERAIS: Rio Acima, 27.V.2005, A. Salino et al. 10503 (BHCB).

Elaphoglossum glabellum caracteriza-se pelo caule curto-reptante, pecíolos aproximados entre si e lâmina coriácea, linear, com margem revoluta e muito estreita (com até $1,5 \mathrm{~cm}$ larg.). As demais espécies registradas em Carajás (Arruda 2014) possuem lâminas estéreis mais largas que $1,5 \mathrm{~cm}$ larg., com exceção de E. gayanum (Fée) T.Moore, a qual pode apresentar a lâmina estéril com menos de $1,5 \mathrm{~cm}$ larg., mas que neste caso pode ser facilmente diferenciada de E. glabellum pelo caule longoreptante e pelos pecíolos bastante distantes entre si, além das escamas do caule castanho-escuras ou bicolores. Em espécimes de outras regiões do país, as frondes férteis podem ser do mesmo tamanho ou maiores que as estéreis.

Neotropical. Brasil: AC, AM, GO, MG, PA, RJ, SP (Prado et al. 2015). Serra dos Carajás: Serra Sul: S11-C, S11-D. Mata baixa e Floresta
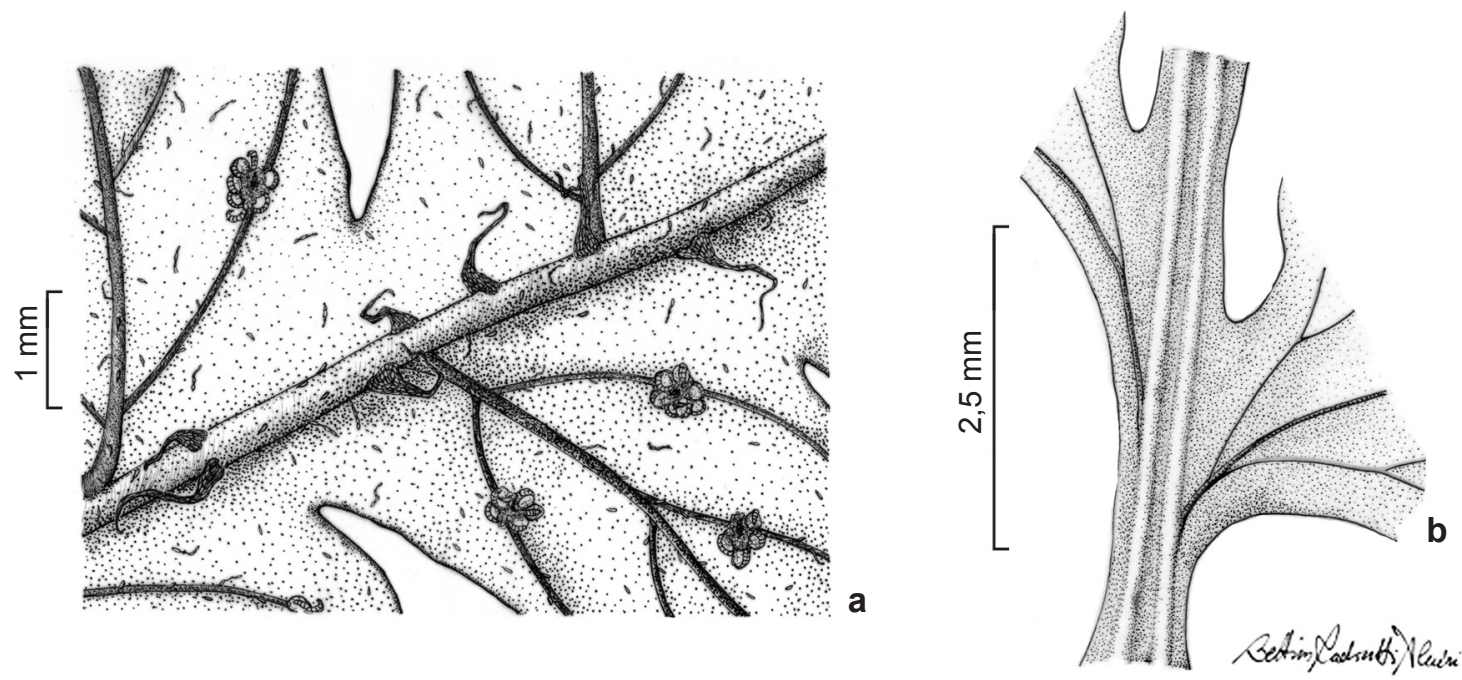

Figura 2 - a. Ctenitis nigrovenia - detalhe da face abaxial dos segmentos mostrando nervuras, soros, tricomas e escamas; b. Dryopteris huberi - detalhe da face adaxial da pina mostrando a costa sulcada (a. A. Salino 15212; b. D.T. Souza 1123).

Figure 2 - a. Ctenitis nigrovenia - detail of abaxial surface of segments showing veins, sori, hairs and scales; b. Dryopteris huberi - detail of adaxial surface of pinna showing sulcate costa (a. A. Salino 15212; b. D.T. Souza 1123). 

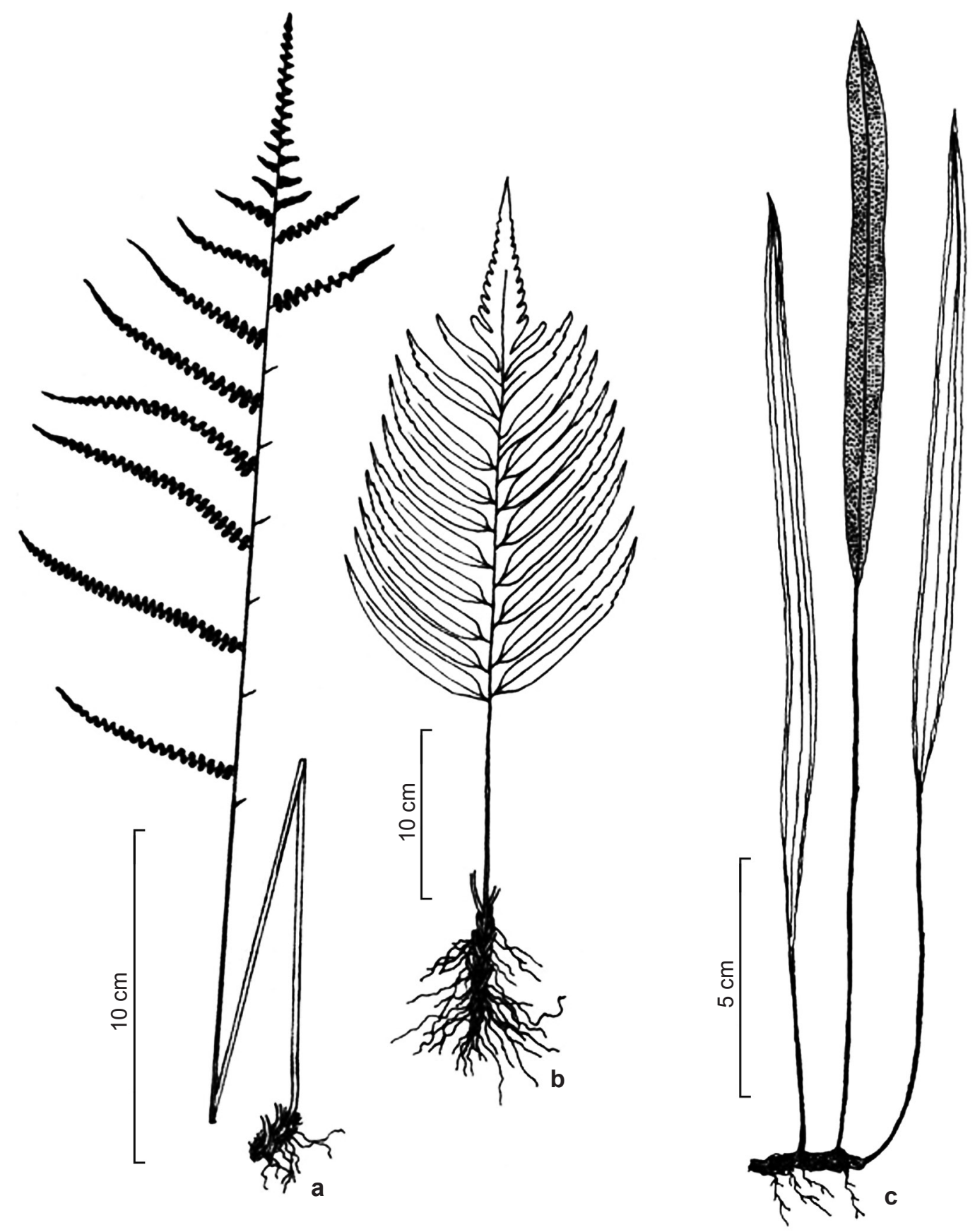

Figura 3 - a-b. Polybotrya sorbifolia - a. fronde fértil; b. fronde estéril. c. Elaphoglossum glabellum - hábito mostrando frondes estéril e fértil (a. S.M.B. Silva 24; b. A. Salino 10713; c. A. Salino 10503).

Figure 3-a-b. Polybotrya sorbifolia - a. fertile frond; b. sterile frond. c. Elaphoglossum glabellum - habit showing sterile and fertile fronds (a. S.M.B. Silva 24; b. A. Salino 10713; c. A. Salino 10503). 
Ombrófila Densa, em encostas úmidas ou a margem de cursos d'água, entre 700 a 790 m de altitude.

4. Polybotrya Humb. \& Bonpl. ex Willd.

Polybotrya é composto por plantas terrícolas, rupícolas ou trepadeiras por meio do caule; que se caracterizam por apresentar caule curto a longoreptante, densamente recoberto por escamas; frondes dimorfas; lâmina estéril 1-4-pinada, lanceolada, com ápice pinatífido; lâmina fértil 1-pinado-pinatífida a 3-pinado-pinatífida; nervuras livres a anastomosadas, sem vênulas livres inclusas; soros arredondados, alongados formando cenosoros ou anfi-acrosticóides; indúsio ausente. Gênero de distribuição neotropical com 37 espécies, das quais 15 no Brasil (Canestraro \& Labiak 2015), seis no Pará (Goés-Neto 2011), três na Serra dos Carajás (Arruda 2014) e uma nas cangas.

\subsection{Polybotrya sorbifolia Mett ex Kuhn, Linnaea} 36(1): 64. 1869.

Fig. 3a-b

Plantas terrícolas ou rupícolas. Caule curtoreptante, com escamas lanceoladas, castanhas, margens denticuladas. Frondes 43,5-110 cm. Pecíolo 22-39,5 cm × 0,8-6,1 mm. Lâmina estéril 21,5-70,5 cm, 1-pinada, pinas 8,8-23,7 $\times 2-3,5 \mathrm{~cm}$, inteiras à serreadas, tecido laminar com glândulas sésseis na face abaxial e esparsas escamas minúsculas em ambas as faces da superfície laminar e nervuras, tricomas simples na costa. Nervuras livres. Lâmina fértil 16,5-52,5 cm compr., 1-pinado-pinatífida, pinas 2,8-13 ×0,4-0,8 $\mathrm{cm}$; soros formando cenosoros.

Material selecionado: Canaã dos Carajás, Serra Sul corpo B, 6²1'18's, 50²3'16"W, 650 m, 06.X.2009, P.L. Viana et al. 4407 (BHCB); Serra Sul, corpo D, 6²4'56"S, 50¹9'34"'W, 655 m, 03.IX.2010, T.E. Almeida et al. 2533 (BHCB); Serra Sul, 6²1'23'"S, $50^{\circ} 23$ '22'”W, 700 m, 19.III.2009, P.L. Viana et al. 4161 (BHCB); Parauapebas: Serra da Bocaina, 6 ${ }^{\circ} 18^{\prime} 45^{\prime}$ S, 4953'53'”W, 700 m, 12.II.2012, A. Salino et al. 15171 (BHCB); Serra Norte, estrada para corpo N1, 559'05'S, 50॰19'03'”W, 268 m, 20.V.2012, A. Salino et al. 15252 (BHCB); Serra Norte, 659'5'S, 50¹9'3"'W, 268 m, 20.V.2012, A.J. Arruda 1151 (BHCB); Serra Norte N4, 66'13"S, 50¹0'36"W, 645 m, 18.V.2012, A.J. Arruda et al. 1135 (BHCB).

Material adicional examinado: BRASIL. MINAS GERAIS: Paracatu, 03.II.2006, A. Salino et al. 10713 (BHCB). MATO GROSSO DO SUL: Aquidauana, 19.III.2005, S.M.B. Silva et al. 24 (BHCB).

Polybotrya sorbifolia se diferencia das demais espécies ocorrentes na região de Carajás (P. caudata Kunze e P. osmundacea Willd.; Arruda 2014) pelo caule curto-reptante e pelo hábito geralmente terrícola ou rupícola, nunca trepador. Polybotrya caudata e P. osmundacea possuem caule longo-reptante e trepador, e possuem a lâmina estéril 2-pinado-pinatífida ou mais dividida.

Costa Rica, Guiana Britânica, Suriname, Venezuela, Colômbia e Brasil: AL, GO, MG, MT, PA, PE, RR, SP (Canestraro \& Labiak 2015). Serra dos Carajás: Serra da Bocaina, Serra Norte: N1, e Serra Sul: S11-B, S11-D. Floresta Ombrófila Densa, em rochas próximas a igarapés e cursos d'água, entre 268 e $700 \mathrm{~m}$ de altitude.

\section{Agradecimentos}

Ao CNPq, a bolsa de Iniciação Científica (Protax - Proc. 440474/2015-9) concedida ao primeiro autor e a bolsa de Produtividade para A. Salino (proc. 306868/2014-8). Ao projeto objeto do convênio MPEG/ITV/FADESP (01205.000250/2014-10) e ao projeto aprovado pelo CNPq (processo 455505/2014-4), o financiamento.

\section{Referências}

Arruda, A.J. 2014. Samambaias e Licófitas das Serras Ferruginosas da Floresta Nacional de Carajás, Pará, Brasil. Dissertação de Mestrado. Universidade Federal de Minas Gerais, Belo Horizonte. 224p.

Canestraro, B.K. \& Labiak, P.H. 2015. The fern genus Polybotrya (Dryopteridaceae) in the Atlantic Forest of Brazil, with the description of a new species. Brittonia 67: 191-215.

Fraser-Jenkins C.R. 1986. A classification of the genus Dryopteris (Pteridophyta: Dryopteridaceae). Bulletin of the British Museum of Natural History (Bot) 14: 183-218.

Góes-Neto, L.A.A. 2011. Licófitas e Samambaias do corredor de biodiversidade do norte. Dissertação de Mestrado. Universidade Federal Rural da Amazônia e Museu Paraense Emílio Goeldi, Belém. 183p.

Mickel, J.T. \& Smith, A.R. 2004. The Pteridophytes of Mexico. Memoirs of the New York Botanical Garden 88: 1-1055.

Prado, J.; Hirai, R.Y. \& Smith, A.R. 2014. Dryopteris huberi (Dryopteridaceae), an overlooked species, and a key for the species of Dryopteris in Brazil. Brittonia 66: 340-346.

Prado, J.; Sylvestre, L.S.; Labiak, P.H.; Windisch, P.G.; Salino, A.; Barros, I.C.L.; Hirai, R.Y.; Almeida, T.E.; Santiago, A.C.P.; Kieling-Rubio, M.A.; Pereira, A.F.N.; Øllgaard, B.; Ramos, C.G.V.; Mickel, J.T.; Dittrich, V.A.O.; Mynssen, C.M.; Schwartsburd, P.B.; Condack, J.P.S.; Pereira, J.B.S. \& Matos, F.B. 2015. Diversity of ferns and lycophytes in Brazil. Rodriguésia 66: 1073-1083.

Skog, J.E.; Mickel, J.T.; Moran, R.C.; Volovsek, M. \& Zimmer, E.A. 2004. Molecular studies 
of representative species in the fern genus Elaphoglossum (Dryopteridaceae) based on cpDNA sequences $r b c \mathrm{~L}$, $t r n \mathrm{~L}-\mathrm{F}$, and $r p s 4-t r n \mathrm{~S}$. International Journal of Plant Sciences 165: 1063-1075.

Smith, A.R.; Pryer, K.M.; Schuettpelz, E.; Korall, P.; Schneider, H. \& Wolf, P.G. 2006. A classification for extant ferns. Taxon 55: 705-731.

Tryon, R.M. \& Tryon, A.F. 1982. Ferns and allied plants with special reference to tropical America. SpringerVerlag, New York. 857p.

Viveros, R.S. 2016. Estudos taxonômicos do gênero Ctenitis (C.Chr.) C.Chr. (Dryopteridaceae -
Polypodiopsida) na América do Sul. Tese de Doutorado. Universidade Federal de Minas Gerais, Belo Horizonte. 211p.

Viveros, R.S. \& Salino, A. 2015. Two new species of Ctenitis (Dryopteridaceae) from South America and taxonomic notes on similar species. Phytotaxa 239: 1-16.

Zhang, L.B.; Zhang, L.; Dong, S.-Y.; Sessa, E.B.; Gao, X.F. \& Ebihara, A. 2012. Molecular circumscription and major evolutionary lineages of the fern genus Dryopteris (Dryopteridaceae). BMC Evolutionary Biology 12: 180.

\section{Lista de exsicatas}

Almeida, T.E. 2178 (1.1), 2179 (4.1), 2210 (1.1), 2212 (2.1), 2251 (3.1), 2533 (4.1); Arruda, A.J. 220 (2.1), 470 (2.1), 548 (4.1), 586 (2.1), 612 (2.1), 1135 (4.1), 1151 (4.1), 1231 (4.1), 1409 (4.1); de Paula, L.F.A. 562 (4.1); Mota, N.F.O. 1962 (4.1); Salino, A. 10503 (3.1), 10713 (4.1), 15145 (1.1), 15171 (4.1), 15178 (1.1), 15181 (4.1), 15212 (1.1), 15252 (4.1), 15259 (2.1), 15291 (1.1), 15575 (1.1); Silva, L.V.C. 1106 (2.1), 1151 (2.1), 1164 (1.1), 1176 (2.1); Silva, S.M.B. 24 (4.1); Souza, D.T. 1083 (3.1), 1094 (2.1), 1111 (2.1), 1123 (2.1), 1145 (3.1), 1146 (3.1), 1164 (1.1); Viana, P.L. 4115 (3.1), 4143 (2.1), 4161 (4.1), 4336 (1.1), 4407 (4.1). 
